\title{
Pristimerin induces apoptosis in imatinib-resistant chronic myelogenous leukemia cells harboring T315I mutation by blocking NF-KB signaling and depleting Bcr-Abl
}

\author{
Zhongzheng Lu¹, Yanli Jin¹, Chun Chen², Juan Li³, Qi Cao and Jingxuan Pan*1
}

\begin{abstract}
Background: Chronic myelogenous leukemia (CML) is characterized by the chimeric tyrosine kinase Bcr-Abl. Bcr-AblT315I is the notorious point mutation that causes resistance to imatinib and the second generation tyrosine kinase inhibitors, leading to poor prognosis. CML blasts have constitutive p65 (RelA NF-kB) transcriptional activity, and NF-kB may be a potential target for molecular therapies in CML that may also be effective against CML cells with Bcr-AblT315l.

Results: In this report, we discovered that pristimerin, a quinonemethide triterpenoid isolated from Celastraceae and Hippocrateaceae, inhibited growth and induced apoptosis in CML cells, including the cells harboring Bcr-Abl-T315I mutation. Additionally, pristimerin inhibited the growth of imatinib-resistant Bcr-Abl-T315I xenografts in nude mice. Pristimerin blocked the TNFa-induced IKBa phosphorylation, translocation of p65, and expression of NF-kB-regulated genes. Pristimerin inhibited two steps in NF-KB signaling: TAK1 TIKK and IKKTIKBa. Pristimerin potently inhibited two pairs of CML cell lines (KBM5 versus KBM5-T315I, 32D-Bcr-Abl versus 32D-Bcr-Abl-T315I) and primary cells from a CML patient with acquired resistance to imatinib. The mRNA and protein levels of Bcr-Abl in imatinib-sensitive (KBM5) or imatinib-resistant (KBM5-T315I) CML cells were reduced after pristimerin treatment. Further, inactivation of Bcr-Abl by imatinib pretreatment did not abrogate the TNFa-induced NF-KB activation while silencing p65 by siRNA did not affect the levels of Bcr-Abl, both results together indicating that NF-KB inactivation and Bcr-Abl inhibition may be parallel independent pathways.

Conclusion: To our knowledge, this is the first report to show that pristimerin is effective in vitro and in vivo against CML cells, including those with the T315I mutation. The mechanisms may involve inhibition of NF-kB and Bcr-Abl. We concluded that pristimerin could be a lead compound for further drug development to overcome imatinib resistance in CML patients.
\end{abstract}

\section{Background}

Chronic myelogenous leukemia (CML) is a myeloproliferative disorder characterized by the presence of Bcr-Abl which is formed by a reciprocal chromosomal translocation $\mathrm{t}(9,22)(\mathrm{q} 34 ; \mathrm{q} 11)[1,2]$. Bcr-Abl is essential for malignant transformation [3], and triggers several cellular signaling pathways (e.g., CrkL, STAT5, PI3K/AKT) to

\footnotetext{
* Correspondence: jingx_pan@yahoo.com.cn

1 Department of Pathophysiology, Zhongshan School of Medicine, Sun Yat-sen University, Guangzhou, PR China

+ Contributed equally

Full list of author information is available at the end of the article
}

regulate cell proliferation, differentiation, migration, survival and DNA repair [4]. Targeting Bcr-Abl has therefore been an important strategy for CML treatment [5]. Imatinib (STI571, Gleevec, Norvartis) effectively inhibits tyrosine kinase activity by occupying the adenosine triphosphate (ATP)-binding pocket of Bcr-Abl, thus abrogating subsequent signal transduction [6]. Of newly diagnosed patients with chronic-phase CML, 82\% showed complete cytogenetic response on treatment with imatinib over a median follow-up of 54 months [7]. However, resistance to imatinib develops over time and is an 
emerging problem for CML patients. Most cases of acquired clinical resistance are due to mutations in the kinase domain of Bcr-Abl. To overcome the acquired resistance, second generation tyrosine kinase inhibitors (e.g., nilotinib, dasatinib and INNO-406) have been developed and are effective against all but the T315I mutation which accounts for approximately $20 \%$ of acquired resistance cases [8-11]. Hence, novel strategies or compounds that can inhibit/kill CML cells carrying Bcr-Abl-T315I are needed.

Abnormal constitutive NF- $\mathrm{KB}$ activation is widely found in diverse types of hematopoietic malignancies (e.g. CML [12], acute myeloid leukemia [13], Hodgkin's disease [14]) as well as solid tumors. In particular, the constitutive activation of NF- $\mathrm{kB}$ exists selectively in leukemia stem cells but not in normal hematopoietic stem cells [15]. Therefore, NF-кB may be a potential therapeutic target for the selective eradication of leukemia stem cells. CML blasts have constitutive p65 (RelA NF-kB) transcriptional activity, and NF- $\mathrm{kB}$ may be a potential target for molecular therapies in CML [16]. Indeed, pharmacological inhibition of NF- $\mathrm{kB}$ was effective in killing CML cells [17].

Pristimerin is a quinonemethide triterpenoid compound isolated from Celastraceae and Hippocrateaceae. Pristimerin has shown antimicrobial, anti-inflammatory, antiperoxidation activities [18] as well as antitumor effects in various types of human cancers [19-21]. Although pristimerin is known to be a potent inhibitor of nuclear factor $\mathrm{kB}(\mathrm{NF}-\mathrm{kB})$-mediated transcription [20], the detail mechanism by which pristimerin inhibits activation of NF- $\mathrm{kB}$ is unknown. In our continuing search for effective compounds to kill CML cells carrying T315IBcr-Abl [22,23], we tested this NF- $\mathrm{BB}$ inhibitor (pristimerin) against CML cells including those carrying T315I-Bcr-Abl, and elaborated the mechanistic detail of the inhibition of NF- $\mathrm{kB}$ by pristimerin. We extended our work to translational studies evaluating the in vivo efficacy of pristimerin against imatinib-resistant cells. We also found that downregulating the levels of Bcr-Abl may also be a relevant antineoplastic mechanism of pristimerin in malignant cells carrying Bcr-Abl.

\section{Methods}

\section{Chemicals and antibodies}

Pristimerin (Figure 1A, purity > 98\%, HPLC) was obtained from Paypaytech Inc. (Shenzhen, China). Pristimerin was dissolved in DMSO (Sigma, Shanghai) at a stock concentration of $10 \mathrm{mM}$, and stored at $-20^{\circ} \mathrm{C}$. Imatinib (STI571) was purchased from Alexis Biochemicals (Plymouth Meeting, PA). Annexin V-FITC, and mouse monoclonal antibody against actin were from SigmaAldrich (Sigma, Shanghai). MG-132 was from Calbiochem (San Diego, CA). Recombinant human TNF $\alpha$ was from Peprotech (Rocky Hill, NJ). Antibodies against p65, IкB $\alpha$, c-Abl (C-19), proliferating cell nuclear antigen (PCNA), IKK $\alpha$, cyclin D1 (C-20), apoptosis-inducing factor (AIF, H300), Bax, Bcl-X , $_{\text {, }}$ acl-1 (S-19) were from Santa Cruz Biotechnology (Santa Cruz, CA). Mouse antibodies against poly(adenosine diphosphate [ADP]ribose) polymerase (PARP, clone 4C10-5), caspase-3, and active caspase-3 (CM1), XIAP, cyclooxygenase-2 (Cox-2), and cytochrome c (clone 6H2.B4) were from BD Biosciences (San Jose, CA). Antibodies against phospho-IKK $\alpha$ (Ser180)/IKK $\beta$ (Ser181), phospho-IKB $\alpha$ at Ser32, phospho-p65 at Ser536, phospho-c-Abl at Y245, phosphoErk1/2 (T202/Y204), Erk1/2, phospho-AKT at Ser473 and AKT were from Cell Signaling Technology (Beverly, MA). Antibodies against phospho-STAT5A/B (Y694/ Y699) (clone 8-5-2), STAT5A, and Bcl-2 were from Upstate Technology (Lake Placid, NY). Anti-phosphoRNA polymerase II (S5) was from Bethyl Laboratories (Montgomery, TX); Anti-survivin was from Novus Biol (Littleton, CO). Anti-mouse immunoglobulin G and antirabbit immunoglobulin $\mathrm{G}$ horseradish peroxidase-conjugated secondary antibodies were from Pierce Biotechnology (Rockford, IL).

\section{Cell culture}

Imatinib-sensitive KBM5 cells bearing 210 kDa wild-type $\mathrm{Bcr}-\mathrm{Abl}$, were grown in Iscove's modified Dulbecco's medium (Invitrogen, Guangzhou, China) supplemented with $10 \%$ heat-inactivated fetal calf serum (FCS), as described previously [22,23]. Imatinib-resistant KBM5T315I cells bearing T315I mutation in Bcr-Abl were routinely maintained in the same medium but with $1.0 \mu \mathrm{M}$ imatinib, which was removed before experiments with a wash-out period of 2-3 days. KBM5 and KBM5-T315I had different sensitivities to imatinib; $\mathrm{IC}_{50}$ values were 0.28-0.53 and 5.04-5.40 $\mu \mathrm{M}$, respectively [22,23]. The 32D myeloid cells stably expressing either $210 \mathrm{kDa}$ wild-type Bcr-Abl (32D-Bcr-Abl) or T315I Bcr-Abl (32D-T315I) were established and maintained in RPMI 1640 with 10\% FCS as described previously [23]. K562 cell was grown in RPMI 1640 with 10\% FCS. U2OS cells were cultured in DMEM with $10 \%$ FCS. Cells in logarithmic phase were used in all experiments starting with $2.0 \times 10^{5}$ cells $/ \mathrm{mL}$.

\section{Primary cells from CML patients}

Peripheral blood samples were obtained from 7 patients with leukemia [5 CML, 1 JMML (juvenile myelomonocytic leukemia), 1 ALL (acute lymphoid leukemia), Additional file 1, Table S1] and 4 healthy adult donors in Sun Yat-sen Memorial Hospital of Sun Yat-sen University, and The First Affiliated Hospital of Sun Yat-sen University after informed consent according to the institutional guidelines and the Declaration of Helsinki principles. Mononuclear cells were isolated by Histopaque gradient 


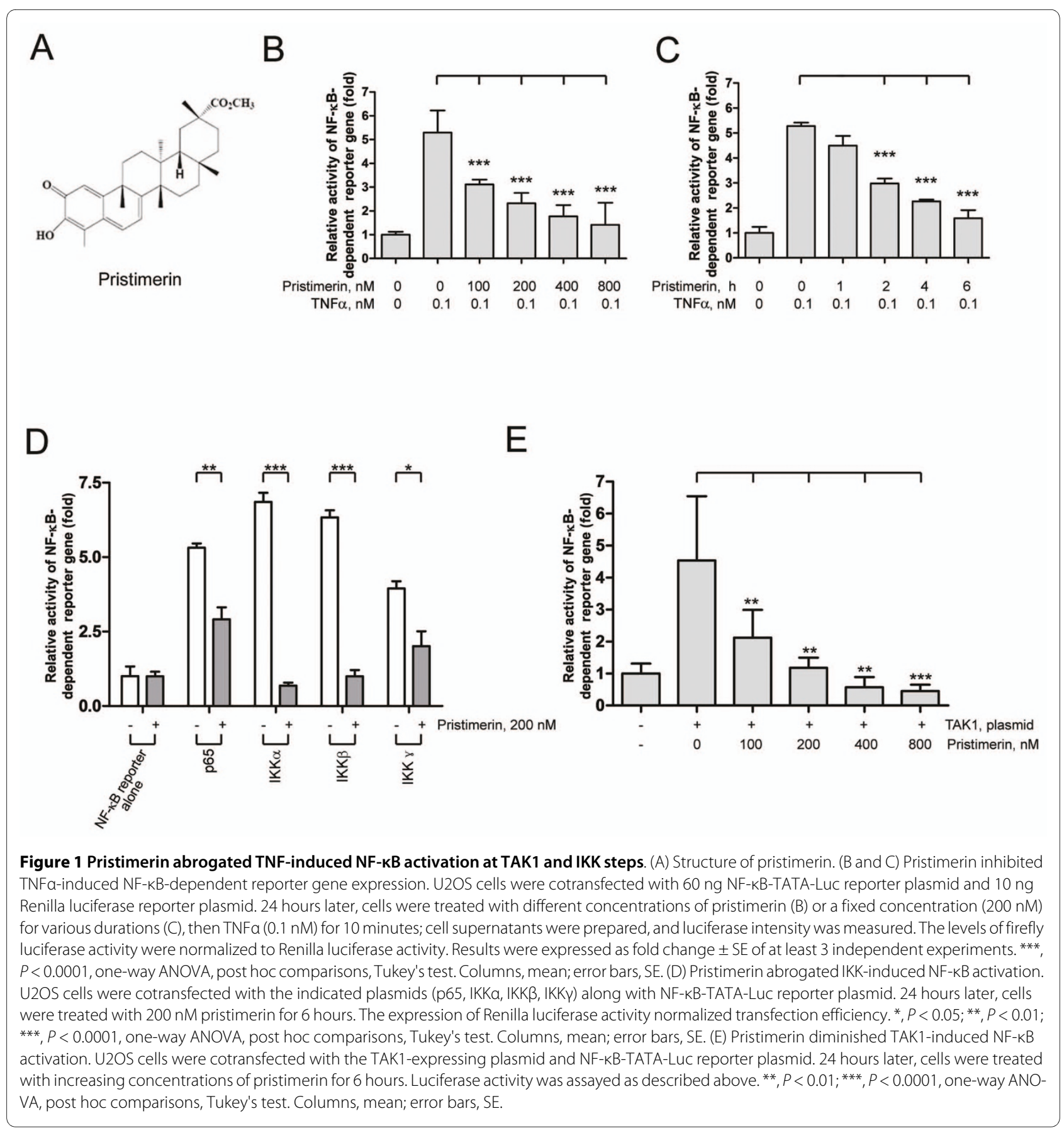

centrifugation (density $1.077 \mathrm{~g} / \mathrm{mL}$; Sigma-Aldrich, Shanghai, China). Contaminating red cells were lysed in $0.8 \%$ ammonium chloride solution for 10 minutes. After washing with PBS, cells were suspended in RPMI 1640 supplemented with $10 \%$ FCS.

\section{Luciferase assay}

U2OS cells $\left(2 \times 10^{5}\right)$ were transfected with reporter plasmids encoding NF-kB-TATA-luc (60 ng) and pEFRenillaluc (10 ng) or together with plasmids encoding the desired genes by use of LipofectAMINE 2000 (Invitrogen). After 24 hours, cells were left untreated or exposed to pristimerin for 6 hours. The cell supernatants were prepared immediately after stimulation with TNF $\alpha(0.1$ $\mathrm{nM}$ ), and luciferase activities were measured with use of dual-luciferase assay kits (Promega, Madison, WI) as described previously [24]. NF- $\mathrm{kB}$ activities were determined by normalization of NF-kB-dependent firefly luciferase to Renilla luciferase activity. The pNF- $k B-L u c$ plasmid was from Stratagene (La Jolla, CA). The plasmids 
pCMV5-IKK $\alpha$, pCMV5-IKK $\beta$, pCMV5-IKK $\gamma$, pCMV5p65, and pCMV5-myc-TAK1 used for co-transfection experiments were described previously [24].

\section{Electrophoretic mobility shift assay (EMSA)}

EMSA involved use of the LightShift Chemiluminescent EMSA kit (Pierce Biotechnology, Shanghai) according to the manufacturer's instructions [24]. The oligonucleotides for NF-kB were from Promega (Shanghai, China): forward, 5-AGT TGA GGG GAC TTT CCC AGG C-3; reverse, 5-G CCT GGG AAA GTC CCC TCA ACT-3. The binding specificity was examined by competition with a 200-fold excess of the unlabeled oligonucleotide probe (cold competitor, Figure 2A, lanes 7 and 14).

\section{Preparation of whole cell lysates and cytosolic fraction}

Control or drug-treated cells were pelleted by centrifugation and rinsed with PBS. The whole lysates were then prepared with RIPA buffer [22,25]. The cytosolic fraction was prepared with digitonin extraction buffer to detect the level of cytochrome $\mathrm{c}$ and AIF in the cytosol, as described previously [22,25].

\section{Preparation of cytoplasmic and nuclear fractions}

TNF $\alpha$ - and/or pristimerin-treated cells were pelleted by centrifugation and rinsed with PBS. Pellets were then resuspended in $200 \mu \mathrm{l}$ ice-cold lysis buffer (10 mM Hepes pH 7.9, $10 \mathrm{mM} \mathrm{KCl,} 0.1 \mathrm{mM}$ EDTA, 0.4\% NP 40 with 1 mM DTT, $0.5 \mathrm{mM}$ PMSF, $1 \mathrm{mM}$ sodium orthovanadate and Complete Protease Inhibitor Mix) by pipetting up and down (without bubbling) about 10 times [24,26]. After incubation on ice for 10 minutes, the lysates were centrifuged at $10,000 \mathrm{~g}$. The supernatants were transferred to fresh tubes and referred to as cytoplasmic extracts. After washing with the lysis buffer, the pellets were vigorously resuspended in nuclear protein extraction buffer with inhibitors (20 mM Hepes, pH 7.9, 0.4 M $\mathrm{NaCl}, 1 \mathrm{mM}$ EDTA with $1 \mathrm{mM}$ DTT, $0.5 \mathrm{mM}$ PMSF, 0.2 $\mathrm{mM}$ sodium orthovanadate and Complete Protease Inhibitor Mix) and centrifuged for 10 minutes at 14,000 g speed at $4^{\circ} \mathrm{C}$. The resultant supernatants were kept as nuclear fractions $[24,26]$.

\section{Immunofluorescence staining}

After being preincubated with or without pristimerin for 6 hours, KBM5 cells were stimulated with TNF $\alpha$. The cells were harvested and cytospinned onto glass slides. After fixation, and permeabilization, immunofluorescence staining was performed as described previously [27].

Reverse transcription quantitative real-time PCR (RT-qPCR) DNA-free total RNA was prepared with RNeasy minicolumns, using the on-column DNAase digestion step (Qiagen, Valencia, CA) and reverse transcribed into
cDNA following the instruction of Invitrogen SuperScript III First-Stand Kit. Quantitative real-time PCR was performed with Roche LightCycler 480 according to the manufacture's recommended protocol. Optimal reaction conditions for amplification of both Bcr-Abl and $18 \mathrm{~S}$ were as follows: 40 cycles of a two-step PCR $\left(95^{\circ} \mathrm{C}\right.$ for 15 $\mathrm{s}, 60^{\circ} \mathrm{C}$ for $\left.20 \mathrm{~s}\right)$ after initial denaturation $\left(95^{\circ} \mathrm{C}\right.$ for $\left.30 \mathrm{~s}\right)$ with $5 \mu \mathrm{l}$ of cDNA reaction by TaKaRa SYBR Premix Ex Taq Kit. The PCR-primers was as follow: Bcr-Abl - sense: 5'-TCCACTCAGCCACTGGATTTAA-3', antisense:

5'-TGAGGCTCAAAGTCAGATGCTACT-3'; Sirt1 sense:

5'-GAGTGGCAAAGGAGCAGATT-3', antisense:

5'-ATGTAACGATTTGGTGGCAA-3'; 18S - sense:

5'-AAACGGCTACCACATCCAAG-3', antisense:

5'-CCTCCAATGGATCCTCGTTA-3'. The mRNA expression of Bcr-Abl or Sirt1 was normalized as described previously [28]. The results of three independent experiments are reported.

\section{Small interfering RNA transfection}

Small interfering RNA (siRNA) duplexes against p65 were from Cell Signaling Technology (Beverly, MA); ONTARGETplus SMARTpoolsiRNA duplexes against human PDGFRa or ON-TARGETplus Non-Targeting Pool siRNA control were from Dharmacon RNA Tech. (Lafayette, CO) [27]. Transfection of either anti-p65, PDGFR $\alpha$ or the control synthesized siRNA duplexes into K562 cells was performed with the Cell Line Nucleofector Kit T (Amaxa, Gaithersburg, MD) and program O-17 according to the manufacturer's instruction [27]. Twentyfour hours after siRNA transfection, the cells were analyzed with Western blotting.

\section{Cell viability assay}

Cell viability was determined by MTS assay (CellTiter 96 Aqueous One Solution Cell Proliferation assay; Promega, Madison, WI) [22,24]. An amount of $100 \mu \mathrm{l}$ cells $(2.0 \times$ $10^{5} / \mathrm{mL}$ ) were seeded in 96-well plates and incubated with various concentrations of pristimerin for 72 hours. Four hours before culture termination, $20 \mu \mathrm{L}$ of MTS solution was added to each well. Absorbance was read on a 96well plate reader at a wavelength of $490 \mathrm{~nm}$. Control cells received DMSO $(<0.1 \%)$ containing medium. The drug concentration resulting in $50 \%$ inhibition of cell growth $\left(\mathrm{IC}_{50}\right)$ was determined.

\section{Soft agar clonogenic assay}

To evaluate anchorage-independent growth of tumor cells, CML cells $\left(2 \times 10^{5} / \mathrm{ml}\right)$ were treated with increasing concentrations of pristimerin or diluent (DMSO, control) for 24 hours, then washed with PBS; the same amounts of viable cells (as determined by trypan blue exclusion assay and a hemocytometer) were subsequently seeded in 6- 


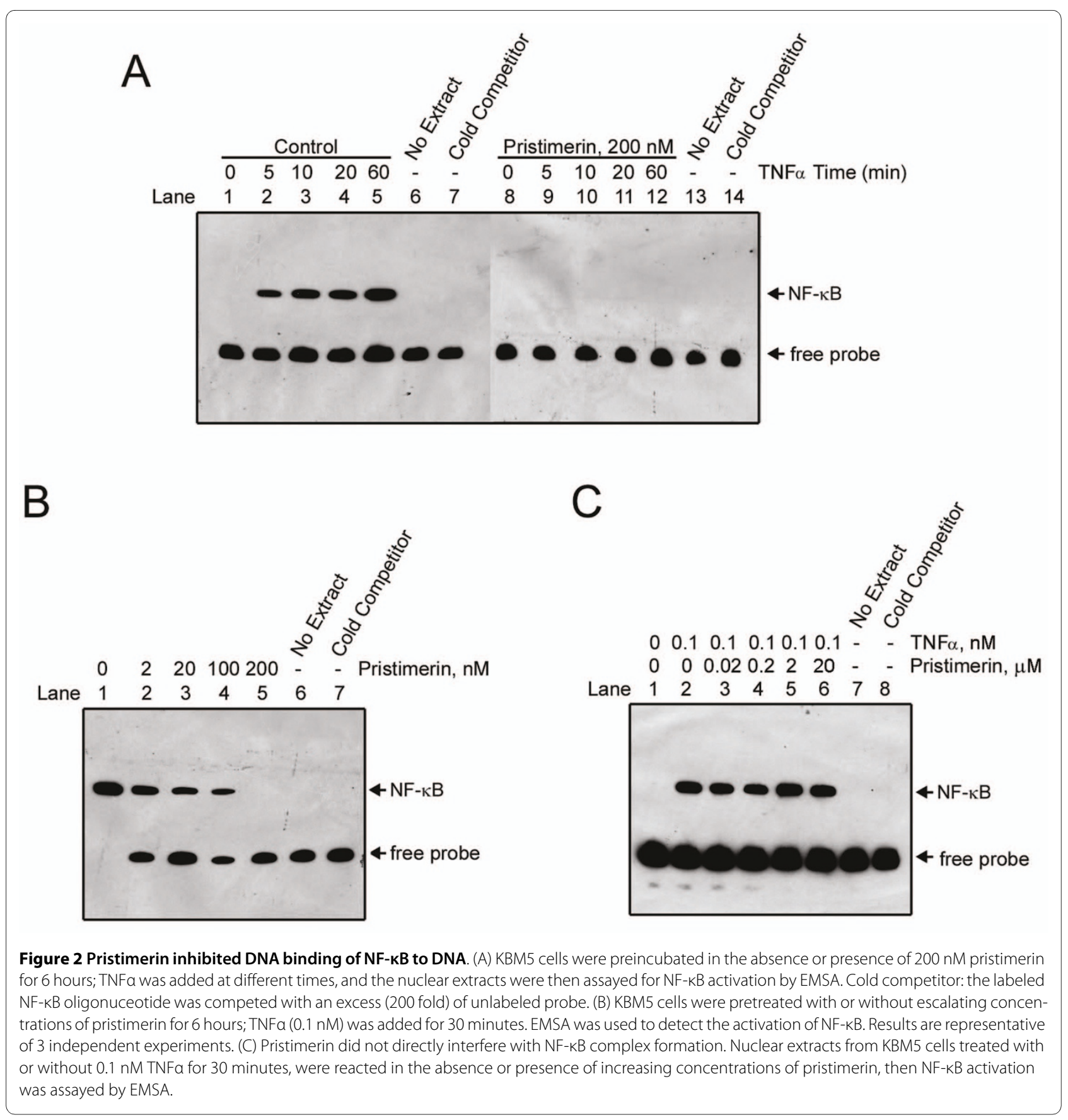

well plates in Iscove's medium containing 0.3\% agar and $20 \%$ FCS in the absence of drug treatment. After incubation for 1014 days at $37^{\circ} \mathrm{C}$, colonies composed of more than 50 cells were counted using an inverted phase-contrast microscope, as described previously [22,24].

\section{Tumor xenograft experiments}

Male $n u / n u$ BALB/c mice were bred at the animal facility of Sun Yat-sen University. The mice were housed in barrier facilities with a 12 -h light dark cycle, with food and water available ad libitum. $3 \times 10^{7}$ of KBM5-T315I cells were inoculated subcutaneously on the flanks of 4- to 6week-old male nude mice. Tumors were measured every other day with use of calipers. Tumor volumes were calculated by the following formula: $a^{2} \times b \times 0.4$, where $a$ is the smallest diameter and $b$ is the diameter perpendicular to $a$. Pristimerin was dissolved in DMSO and diluted with vehicle [30\% Cremophor EL/ethanol (4:1), 70\% PBS]. Mice in the control group received the same amount of vehicle treatment. The body weight, feeding behavior and motor activity of each animal were monitored as indicators of general health. The animals were then euthanized, 
and tumor xenografts were immediately removed, weighed, stored and fixed. All animal studies were conducted with the approval of the Sun Yat-sen University Institutional Animal Care and Use Committee.

\section{Immunohistochemical staining}

Formalin-fixed xenografts were embedded in paraffin and sectioned according to standard techniques. Tumor xenograft sections $(4 \mu \mathrm{m})$ were immunostained using the MaxVision kit (Maixin Biol, Fuzhou, China) according to the manufacturer's instructions [22,23].

\section{Flow cytometry analysis Cell cycle analysis}

Cells treated and control were harvested, washed with PBS, and fixed with $66 \%$ ethanol over night. Cells were centrifuged and washed with PBS, then stained with 50 $\mu \mathrm{g} / \mathrm{mL}$ propidium iodide and $2.5 \mu \mathrm{g} / \mathrm{mL}$ RNase in PBS solution for 30 minutes at room temperature. DNA content was analyzed by flow cytometry at the emission wavelength of $488 \mathrm{~nm}$ [22].

\section{Apoptosis measurement}

Apoptosis was measured by flow cytometry using Annexin V/Propidium iodide (PI) double staining. Cells were cultured in the presence of indicated concentrations of pristimerin for 24 hours, harvested and washed, and incubated in binding buffer (Annexin V Binding Buffer, BD Pharmingen) with $0.3 \%$ Annexin V-FITC for 15 minutes at room temperature. The cells were washed and resupended in binding buffer. Propidium iodide was added just before flow cytometric analysis [22,24].

\section{Statistical analysis}

GraphPad Prism 4.0 software (GraphPad Software, San Diego, CA) was used for statistical analysis. Comparisons between 2 groups involved two-sided Student's $t$ test, and comparisons among multiple groups involved one-way ANOVA with post-hoc intergroup comparisons using Tukey test. $P<0.05$ was considered statistically significant.

\section{Results}

\section{Pristimerin inhibits TNF-induced NF-kB-dependent} reporter gene transcription

We first examined whether pristimerin affected the TNF $\alpha$-induced NF- $\mathrm{B}$-dependent reporter gene transcription. One day after cotransfection with pNF-kBTATA-Luc and pEFRRenilla-Luc, U2OS cells were exposed to pristimerin at increasing concentrations for 6 hours or a fixed concentration $(200 \mathrm{nM})$ for different durations. Prior to the termination of culture, TNF $\alpha$ was added for 10 minutes. The luciferase activity detected was increased by TNF $\alpha$ (Figure 1B); but pristimerin inhibited the $\mathrm{TNF} \alpha$-induced $\mathrm{NF}-\mathrm{\kappa} B$ reporter activity in a dose- and time-dependent manner (Figure $1 \mathrm{~B}$ and $1 \mathrm{C}$ ).
Pristimerin inhibits NF-KB activation induced by $\mathrm{p} 65$, IKKa, IKK $\beta$, IKK $\gamma$ and TAK1

In the canonical NF- $\mathrm{B}$ activation pathway, TAK1 and IKK are the major upstream regulators of $I \kappa B \alpha$. To determine the steps at which pristimerin acted, U2OS cells were cotransfected with plasmids to express IKK $\alpha, \operatorname{IKK} \beta$ or IKK $\gamma$, along with an NF-kB-TATA-Luc reporter plasmid. The luciferase activity of NF-кB-TATA-Luc reporter was significantly increased when cotransfected with $\mathrm{p} 65$, $\mathrm{IKK} \alpha, \mathrm{IKK} \beta$, or IKK $\gamma$ constructs (Figure 1D) compared with transfection with reporter alone. However, addition of pristimerin significantly inhibited the NF- $\mathrm{kB}$ transcriptional activity (Figure 1D). Therefore, pristimerin could block NF- $\mathrm{kB}$ activation induced by IKK overexpression.

Because TAK1 is critical upstream regulator of IKK [29], we assessed the effect of pristimerin on cotransfection of a TAK1 construct along with NF-кB-TATA-Luc reporter plasmid. TAK1 significantly elevated NF-kB reporter luciferase activity (Figure $1 \mathrm{E}$ ), and pristimerin significantly blocked TAK1-induced NF-kB activation.

Pristimerin inhibits DNA binding of NF-KB in intact cells but does not directly interfere with binding of NF-KB to DNA in a purified nuclear extract

We next examined whether pristimerin interfered with the binding of NF- $\mathrm{kB}$ to DNA by EMSA. KBM5 cells were preincubated with or without $200 \mathrm{nM}$ pristimerin for 6 hours; TNF $\alpha$ was added for the indicated times, then nuclear extracts were assayed for NF- $\mathrm{kB}$ DNA binding activity by EMSA with a probe representing an NF- $\mathrm{kB}$ binding site. After stimulation with TNF $\alpha$, the levels of the NF-kB-DNA complex were steadily increased over time in the absence of pristimerin (Figure 2A, lanes 2-5 versus lane 1$)$. With the same durations of stimulation with TNF $\alpha, N F-\kappa B-D N A$ complex were not formed in the presence of $200 \mathrm{nM}$ pristimerin (Figure 2A, lanes 8-12). Competition with an excess (200-fold) of unlabeled probe led to disappearance of the TNF $\alpha$-induced bound complex (Figure 2A, lanes 7 and 14), which confirmed the binding specificity of this assay. Pretreatment for 6 hours with increasing concentrations of pristimerin abrogated TNF $\alpha$-induced NF- $\mathrm{B}$-DNA complex formation in a dose-dependent manner (Figure $2 \mathrm{~B}$ ).

To address whether pristimerin exerted a direct inhibitory effect on the binding of NF- $\mathrm{kB}$ to DNA, nuclear extracts prepared from untreated KBM5 cells or cells stimulated with TNF $\alpha$ were incubated in a cell-free reaction system in the presence of increasing concentrations of pristimerin. Pristimerin, even at a concentration as high as $20 \mu \mathrm{M}$, did not block the TNF $\alpha$-induced formation of NF-kB-DNA complex (Figure 2C), suggesting that pristimerin did not directly interfere with binding of NF$\mathrm{\kappa B}$ to DNA in a purified nuclear extract. 


\section{Pristimerin inhibits TNFa-induced degradation of IKBa and translocation of $\mathrm{p} 65$}

The findings that pristimerin inhibited TNF $\alpha$-induced $\mathrm{NF}-\mathrm{kB}$ transcriptional function and formation of an NF$\kappa \mathrm{B}-\mathrm{DNA}$ binding complex predicted that pristimerin would affect $\mathrm{I} \kappa \mathrm{B} \alpha$ phosphorylation and p65 translocation. To test this hypothesis, KBM5 or KBM5-T315I were pretreated with $200 \mathrm{nM}$ pristimerin for 6 hours, then stimulated with TNF ; cytoplasmic and nuclear extracts were examined by Western blot analysis with antibodies against total and phosphorylated forms of TAK1, IKK $\alpha / \beta$, I $\mathrm{KB} \alpha$ and $\mathrm{p} 65$, respectively. In the absence of pristimerin (Figure 3A, left, control), the levels of phosphorylated TAK1 and phosphorylated IKK $\alpha / \beta$ in the cytoplasmic fraction of KBM5 cells were appreciably increased starting at 5 minutes after TNF $\alpha$ stimulation as compared with untreated cells. The levels of phosphorylated IкB $\alpha$ appeared as a pulse signal that peaked at 5 minutes after TNF $\alpha$ stimulation and then decreased back to baseline (Figure 3A) as previously reported by Anand et al. [30]. Subsequently (starting 5 minutes after TNF $\alpha$ stimulation), the levels of total I $\mathrm{KB} \alpha$ protein in the cytoplasmic fractions decreased, which was consistent with activation of ubiquitination and proteasomal degradation triggered by the phosphorylation of $I_{\kappa} B \alpha$ [31]. In contrast, pristimerin completely abolished the phosphorylation of $\mathrm{IKK} \alpha / \beta$ and $\mathrm{I} \kappa \mathrm{B} \alpha$ induced by TNF $\alpha$ (Figure $3 \mathrm{~A}$, left, pristimerin). Accordingly, the TNF $\alpha$-induced I $\mathrm{B} \alpha \alpha$ degradation was abrogated by pristimerin. The levels of phosphorylated and total p65 in the nuclear fractions were increased in TNF $\alpha$-stimulated cells (Figure 3B, left, control). The increase in nuclear p65 was markedly abrogated by the pristimerin (Figure 3B, left, pristimerin). Similar findings were obtained in KBM5-T315I cells (Figure $3 \mathrm{~A}$ and $3 \mathrm{~B}$, right panels). Further, pristimerin timeand dose-dependently abrogated the TNF $\alpha$-induced IкB $\alpha$ degradation and p65 translocation (Figure 3C). The inhibitory effect of pristimerin on TNF $\alpha$-induced translocation of p65 was further confirmed by immunofluorescent microscopy (Figure 3D).

Pristimerin inhibits TNFa-dependent IKBa phosphorylation Because $I \alpha B \kappa$ phosphorylation is a critical step to tag the protein and trigger ubiquitination-proteosome-dependent degradation of IкB $\alpha$ [32], we next examined whether pristimerin inhibited the degradation of $\mathrm{I} \kappa \mathrm{B} \alpha$ via inhibiting $I \kappa B \alpha$ phosphorylation. TNF $\alpha$ stimulation elevated the levels of phosphorylated IkB $\alpha$ in KBM5 cells (Figure 3E), which was potentiated by the presence of the proteosome inhibitor MG-132. However, pristimerin completely blocked the TNF $\alpha$-induced phosphorylation of IкB $\alpha$ even in the presence of MG-132.
Pristimerin prevents TNFa from inducing NF-кB-dependent gene products involved in survival and apoptosis

It is believed that the pro-survival function of NF- $\mathrm{KB}$ is mediated through NF-kB-regulated expression of cell survival proteins whose genes containing an NF- $\mathrm{kB}$ binding site in their promoters (e.g., Bcl- $\mathrm{X}_{\mathrm{L}}$, survivin, Mcl-1, cyclin D1, c-myc, Bcl-2, and Cox 2) [30]. Because pristimerin inhibits TNF $\alpha$-induced activation of NF-kB, we hypothesized that it would also inhibit TNF $\alpha$-induced expression of cell survival proteins. K562 cells were treated with or without $400 \mathrm{nM}$ pristimerin for 6 hours, followed by stimulation with TNF $\alpha$ for up to 24 hours. The levels of Bcl-X $\mathrm{L}_{\mathrm{L}}$, survivin, Mcl-1, cyclin D1, c-myc, Bcl-2, and Cox 2 as detected by immunoblotting were increased after TNF $\alpha$ stimulation (Figure 3F), and the TNF $\alpha$-induced upregulation of these genes was abolished by pristimerin (Figure 3F).

\section{Pristimerin decreases Bcr-Abl mRNA and inactivates its downstream signaling}

We also examined the effect of pristimerin on the expression of Bcr-Abl in CML cells by immunoblotting. Twenty-four-hour treatment with pristimerin dose- and time-dependently decreased levels of $\mathrm{Bcr}-\mathrm{Abl}$ protein in KBM5, KBM5-T315I or K562 cells (Figure 4A). Bcr-Abl can activate multiple signal transduction pathways (e.g., CrkL, STAT5, Erk1/2, and PI3K/AKT) which can promote cell proliferation and resistance to apoptosis [3]. We reasoned that the loss of total Bcr-Abl protein would lead to a decrease in its kinase activity. We measured autophosphorylation by immunoblotting with the phosphospecific antibody against the phosphorylated Y245 c-Abl as described previously [33]. Basal phosphorylation of Bcr-Abl was detectable in KBM5, KBM5-T315I and K562 cells (Figure 4A). As expected, pritstimerin potently decreased the amount of phosphorylated Bcr-Abl in accord with decrease in the total Bcr-Abl protein (Figure 4A). To better define the effect of pristimerin on Bcr-Abl signaling, we followed the phosphorylation of Bcr-Abl and its downstream targets over time. The levels of Bcr$\mathrm{Abl}$ and phosphorylated Bcr-Abl started to decrease as early as 3 hours after pristimerin treatment, and continued to decrease up to 24 hours after pristimerin treatment (Figure 4B). Concomitantly, the phosphorylation of CrkL, STAT5, Erk1/2 and AKT decreased (Figure 4B). The total protein levels of STAT5 and AKT did decrease at later time points. Taken together, pristimerin decreased Bcr-Abl and inhibited its downstream signaling. Notably, the decrease in Bcr-Abl protein levels preceded the onset of apoptosis, as indicated by specific PARP cleavage and caspase- 3 activation after pristimerin treatment (Figure $4 \mathrm{C}$ ).

To investigate whether the proteosome pathway was involved in the pristimerin-mediated downregulation of 


\section{Figure 3}
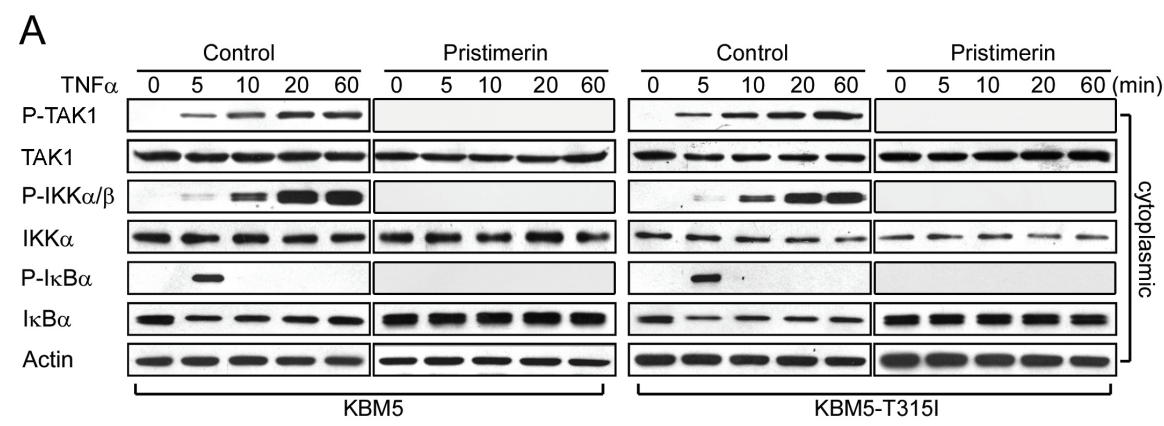

B
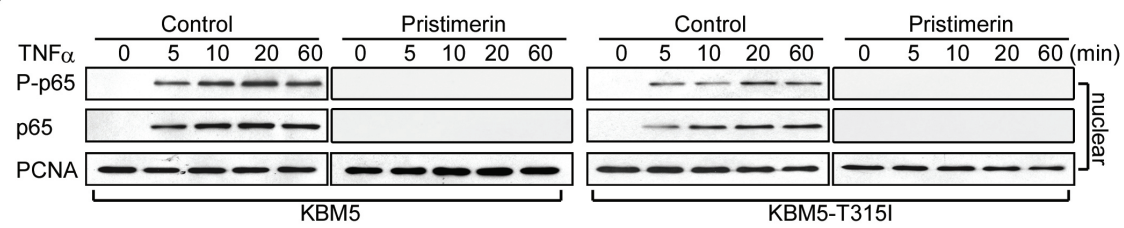

C

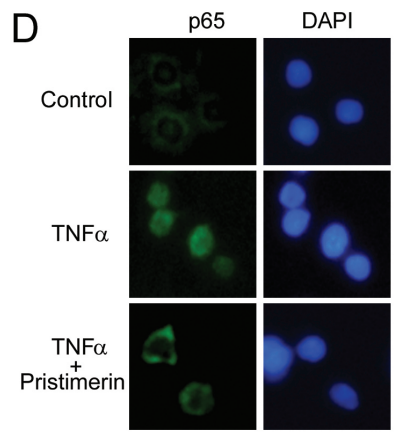

$\mathrm{E}$

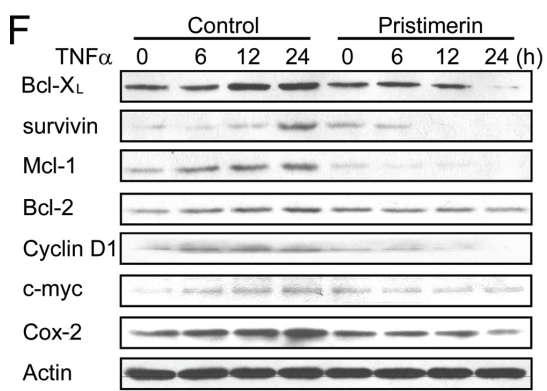

Figure 3 Pristimerin inhibits TNFa-induced degradation of ІкBa and translocation of p65. KBM5 or KBM5-T315I cells were pretreated with or without $200 \mathrm{nM}$ pristimerin for 6 hours, then treated with TNFa $(0.1 \mathrm{nM})$ at the indicated times; cytoplasmic (A) and nuclear (B) extracts were examined by Western blot analysis with specific antibodies against total and phosphorylated IKBa, IKK and p65, respectively. The same membranes were stripped and reprobed with actin or PCNA. (C) Dose- and time-dependent effect of pristimerin. KBM5 cells were preincubated with the indicated concentrations of pristimerin for 6 hours (left) or $200 \mathrm{nM}$ pristimerin for various durations (right); then treated with TNFa (1 nM) for 5 minutes; cytoplasmic and nuclear extracts were examined by Western blot analysis. (D) Immunofluorescence staining analysis of p65. KBM5 cells were preincubated with 200 $\mathrm{nM}$ pristimerin for 6 hours, and TNFa (1 nM) for 5 minutes, fixed in 3\% paraformaldehyde, then underwent immunofluorescence analysis against p65 and FITC-conjugated secondary antibody. Nuclei were stained with 4,6-diamidino-2-phenylindole (DAPI). (E) Pristimerin prevented the phosphorylation of IKBa in the presence of proteosome inhibitor. KBM5 cells were treated with $500 \mathrm{nM}$ pristimerin in the absence or presence of MG-132 (0.5 $\mu \mathrm{M})$ for 6 hours, then treated with TNFa $(0.1 \mathrm{nM})$ for 30 minutes. Cytoplasmic extracts of cells underwent immunoblotting with phosphopecific anti-IKBa. (F) Pristimerin diminishes the expression of NF-KB-regulated proteins involved in survival. Western blot analysis of K562 cells pretreated with $400 \mathrm{nM}$ pristimerin for 6 hours, then stimulated with TNFa (1 nM) for different times. 

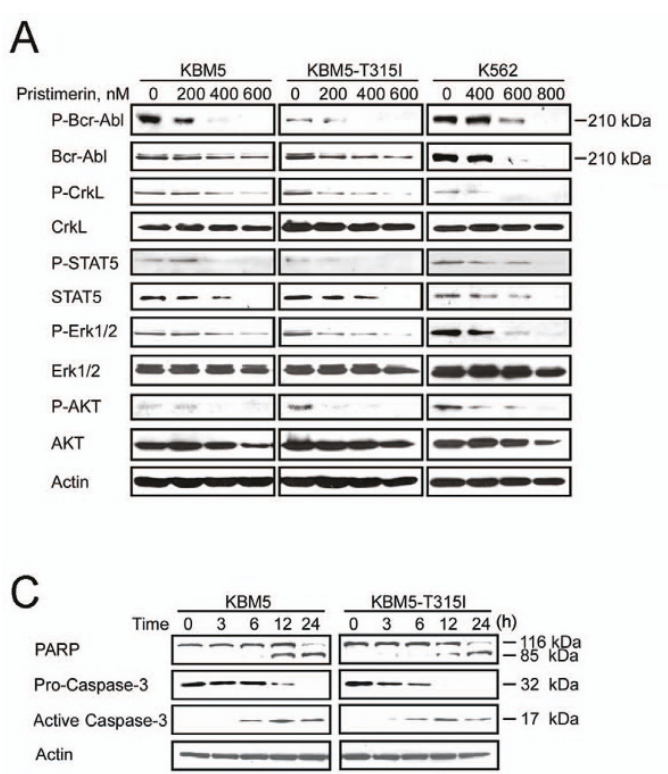

E
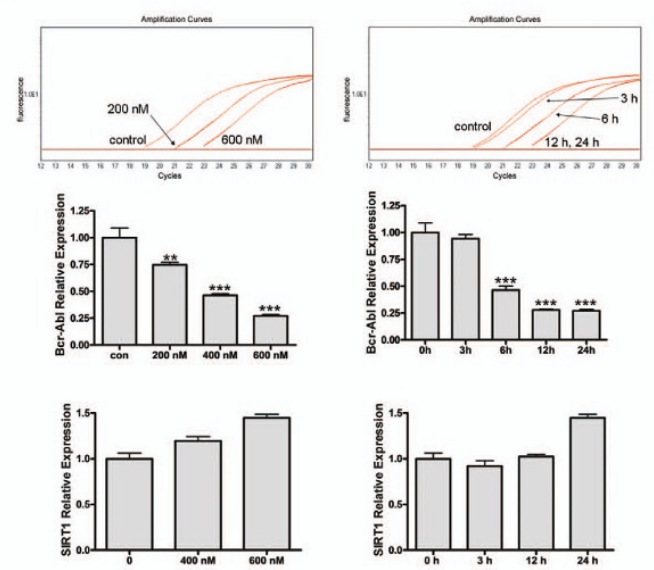

G

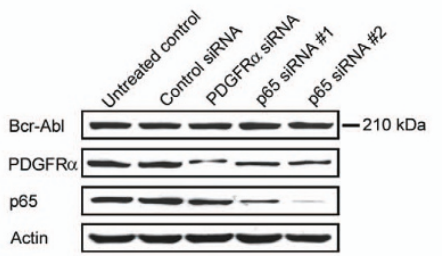

B
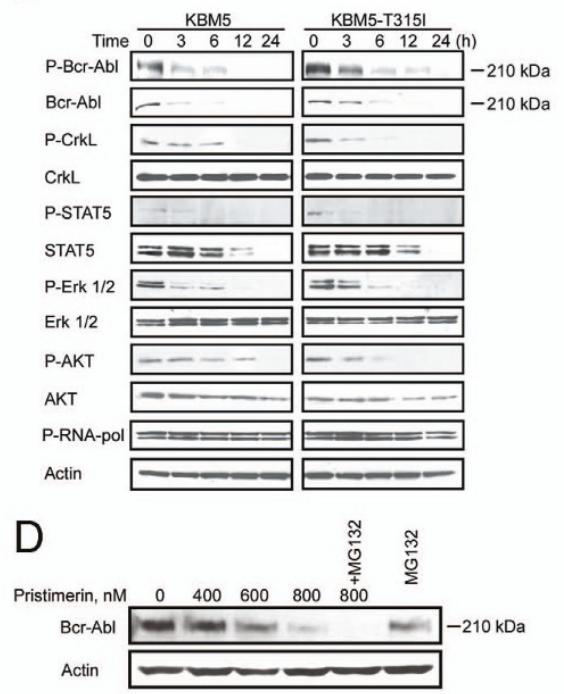

$\mathrm{F}$
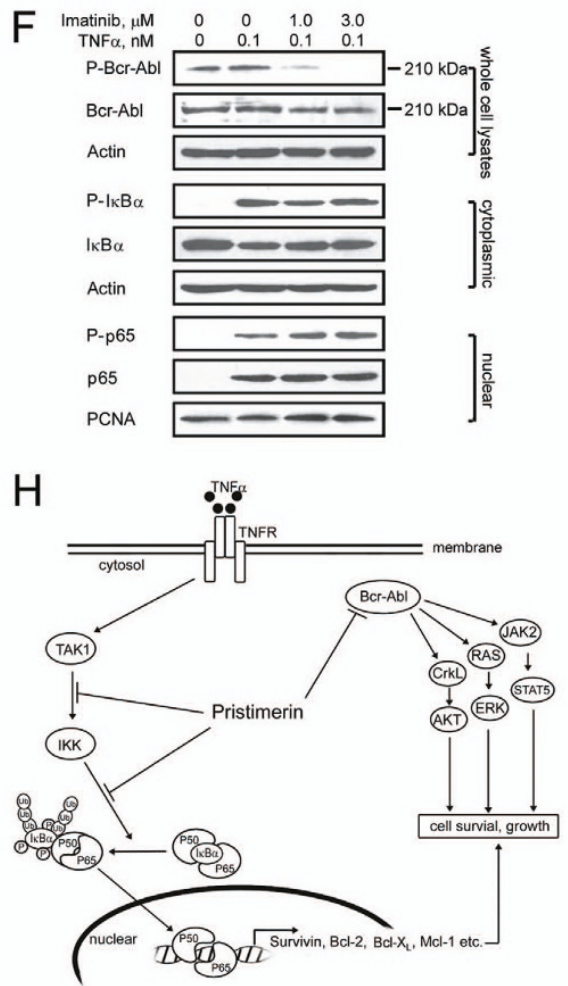

Figure 4 Decreasing Bcr-Abl and its downstream signaling, and inhibiting NF-KB may be independent mechanisms of actions of pristimerin. (A) Dose-dependent downregulation of Bcr-Abl protein by pristimerin. CML cells were exposed to pristimerin for 24 hours, whole cell lysates were subjected to immunoblotting analysis. (B and C) CML cells were treated with $600 \mathrm{nM}$ pristimerin for different durations, downstream signaling mole-

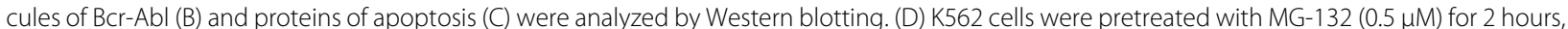
then exposed to pristimerin for another 24 hours. Immunoblots were shown. (E) Pristimerin inhibits Bcr-Abl mRNA levels as measured by RT-qPCR. KBM5 cells were exposed to escalating concentrations of pristimerin for 24 hours (left top and middle) or $600 \mathrm{nM}$ for various durations (right top and middle). The Bcr-Abl mRNA expression relative to the control was calculated by dividing the comparative expression levels. Colomns, mean;bars, $95 \%$ confidence intervals, $\mathrm{n}=3$. Similar data for Sirt1 (an unrelated control gene) were also shown (bottom). ${ }^{* *}, P<0.01 ;{ }^{* *}, P<0.0001$, one-way ANOVA, post-hoc comparisons, Tukey's test. (F) KBM5 cells were pretreated with 1.0-3.0 $\mu \mathrm{M}$ imatinib for 1 hour, the cells were then stimulated with TNFa (0.1 nM, 5 minutes), NF-KB activation was analyzed with Western blotting. (G) K562 cells were transfected with siRNA duplexes against either human p65, PDGFRa or control siRNA, respectively. Twenty-four hours later, the cells were analyzed by Western blotting. $(\mathrm{H})$ A proposed model to delineate the actions of pristimerin. 
Bcr-Abl, we pretreated K562 cells with a sub-cytotoxic concentration $(0.5 \mu \mathrm{M})$ of the proteosome inhibitor MG132 , but found no effect on the decrease in Bcr-Abl protein levels (Figure 4D). Similarly, the pristimerin-induced decrease of $\mathrm{Bcr}-\mathrm{Abl}$ protein was not rescued by the presence of caspase-3 inhibitor z-DEVD-fmk (data not shown).

We next examined whether pristimerin inhibited Bcr$\mathrm{Abl}$ at the transcriptional levels. KBM5 and KBM5-T315I cells were exposed to various concentrations of pristimerin for 24 hours (left) or $600 \mathrm{nM}$ for different durations (right); reverse transcription quantitative real-time PCR (RT-qPCR) revealed that the mRNA levels of BcrAbl were decreased after treatment with pristimerin (Figure 4E) while the mRNA levels of Sirt1 gene (an unrelated gene control) were not decreased, suggesting a selective activity of pristimerin against Bcr-Abl transcription.

The possibility of interdependence of the two actions of pristimerin (i.e., NF- $\mathrm{kB}$ inactivation and depletion of Bcr$\mathrm{Abl})$ was tested. First, we examined whether the TNF $\alpha$ induced NF- $\mathrm{KB}$ activation was dependent on Bcr-Abl. We pretreated KBM5 cells with 1.0-3.0 $\mu \mathrm{M}$ imatinib for 1 hour to inactivate Bcr-Abl, the cells were then stimulated with TNF $\alpha$ (0.1 nM, 5 minutes), followed by analysis of $\mathrm{NF}-\mathrm{kB}$ activation. Imatinib treatment led to dephosphorylation of $\mathrm{Bcr}-\mathrm{Abl}$, which, however, did not abrogate the TNF $\alpha$-induced I $\mathrm{I} B \alpha$ phosphorylation, and subsequent relocation of p65 (Figure 4F). Second, we employed the siRNA approach to determine the effect of p65 on BcrAbl in CML cells. The levels of p65 were appreciably decreased in $\mathrm{K} 562$ cells 24 hours after transfection with siRNA duplexes specifically against p65 when compared with control siRNA and PDGFR $\alpha$ siRNA (unrelated gene control) (Figure 4G). Silencing p65 did not affect the levels of Bcr-Abl. The above results together implicate that $\mathrm{NF}-\mathrm{kB}$ inactivation and $\mathrm{Bcr}-\mathrm{Abl}$ inhibition may be parallel independent pathways.

\section{Pristimerin inhibits growth of imatinib-sensitive and imatinib-resistant CML cells}

We then evaluated the effect of pristimerin on the growth of CML cells. Human CML cell lines (KBM5, KBM5T315I and K562), and a pair of murine myeloid cells 32D stably transfected with either the wild-type or T315I human Bcr-Abl were exposed to escalating concentrations of pristimerin for $72 \mathrm{~h}$, followed by the MTS assay. Cell viability of all 5 lines of CML cells was inhibited, with $\mathrm{IC}_{50}$ values of $199 \mathrm{nM}, 135 \mathrm{nM}, 450 \mathrm{nM}, 242 \mathrm{nM}$ and 387 $\mathrm{nM}$, respectively (Figure 5A). These data suggest similar sensitivities of imatinib-sensitive and imatinib-resistant CML cells to pristimerin.

Because clonogenicity is believed to better reflect malignant behavior of tumor cells, we compared the impact of pristimerin on clonogenicity in CML cells with that of imatinib. We examined the clonogenicity of KBM5 and KBM-T315I cells after a 24 hour-treatment of imatinib. The $\mathrm{IC}_{50}$ values of KBM5 and KBM5-T315I to imatinib were $0.45 \mu \mathrm{M}$ and $4.10 \mu \mathrm{M}$, respectively (data for dose-response curves not shown). The results confirmed the resistance of KBM5-T315I cells to imatinib. In contrast, pristimerin treatment potently inhibited the number of surviving clonogenic KBM5, KBM5-T315I and $\mathrm{K} 562$ cells in a dose-dependent manner, with $\mathrm{IC}_{50}$ values of $43.7 \mathrm{nM}, 35.9 \mathrm{nM}$ and $36.5 \mathrm{nM}$, respectively (Figure 5B).

\section{Primary leukemia cells from imatinib-resistant $\mathrm{CML}$ patient are also sensitive to pristimerin}

We next ascertained the activity of pristimerin against imatinib-resistant primary CML cells. Mononuclear cells in peripheral blood from $1 \mathrm{CML}$ patient who acquired clinical resistance to imatinib versus $4 \mathrm{CML}$ patients that responded to imatinib were exposed to various concentrations of pristimerin for 72 hours. The primary CML cells were sensitive to pristimerin as well, with $\mathrm{IC}_{50}$ values 6-578 nM (Table 1). In particular, the primary leukemia cells from $1 \mathrm{CML}$ patient with acquired clinical resistance to imatinib were also sensitive to pristimerin $\left(\mathrm{IC}_{50}\right.$ value $578 \mathrm{nM}$ ). Of interest, primary leukemia cells from 1 patient with JMML (juvenile myelomonocytic leukemia) and 1 patient from ALL (acute lymphoid leukemia) were also sensitive to pristimerin (Table 1).

We also examined the effect of pristimerin on normal bone marrow cells. Normal bone marrow cells collected from 4 healthy donors were treated with increasing concentrations of pristimerin for $72 \mathrm{~h}$; cell viability assayed by MTS indicated that pristimerin was cytotoxic to normal bone marrow cells with a median $\mathrm{IC}_{50}$ value of 740.5 $\mathrm{nM}$ (range, 681-999 nM). These data were in line with the report by Costa et al. [19] who showed that pristimerin inhibited the cell viability of peripheral blood mononuclear cells with an $\mathrm{IC}_{50}$ value of $880 \mathrm{nM}$. Therefore, bone marrow suppression may be a significant side effect of pristimerin.

\section{Pristimerin inhibits the growth of xenografted KBM5-T315I cells in nude mice}

We next evaluated the in vivo activity of pristimerin against imatinib-resistant CML cells using the nude mouse xenograft model. Twenty six $n u / n u$ BALB/c mice were injected with KBM5-T315I cells. Five days after inoculation of tumor cells, when the size of tumor reached approximately $50 \mathrm{~mm}^{3}$, mice inoculated with KBM5-T315I cells were randomized to receive intratumoral injection with either $50 \mu \mathrm{L}$ vehicle [30\% Cremophor EL/ethanol (4:1), 70\% PBS] or $1.0 \mathrm{mg} / \mathrm{kg}$ pristimerin in vehicle daily during days 6-19 after inoculation of 


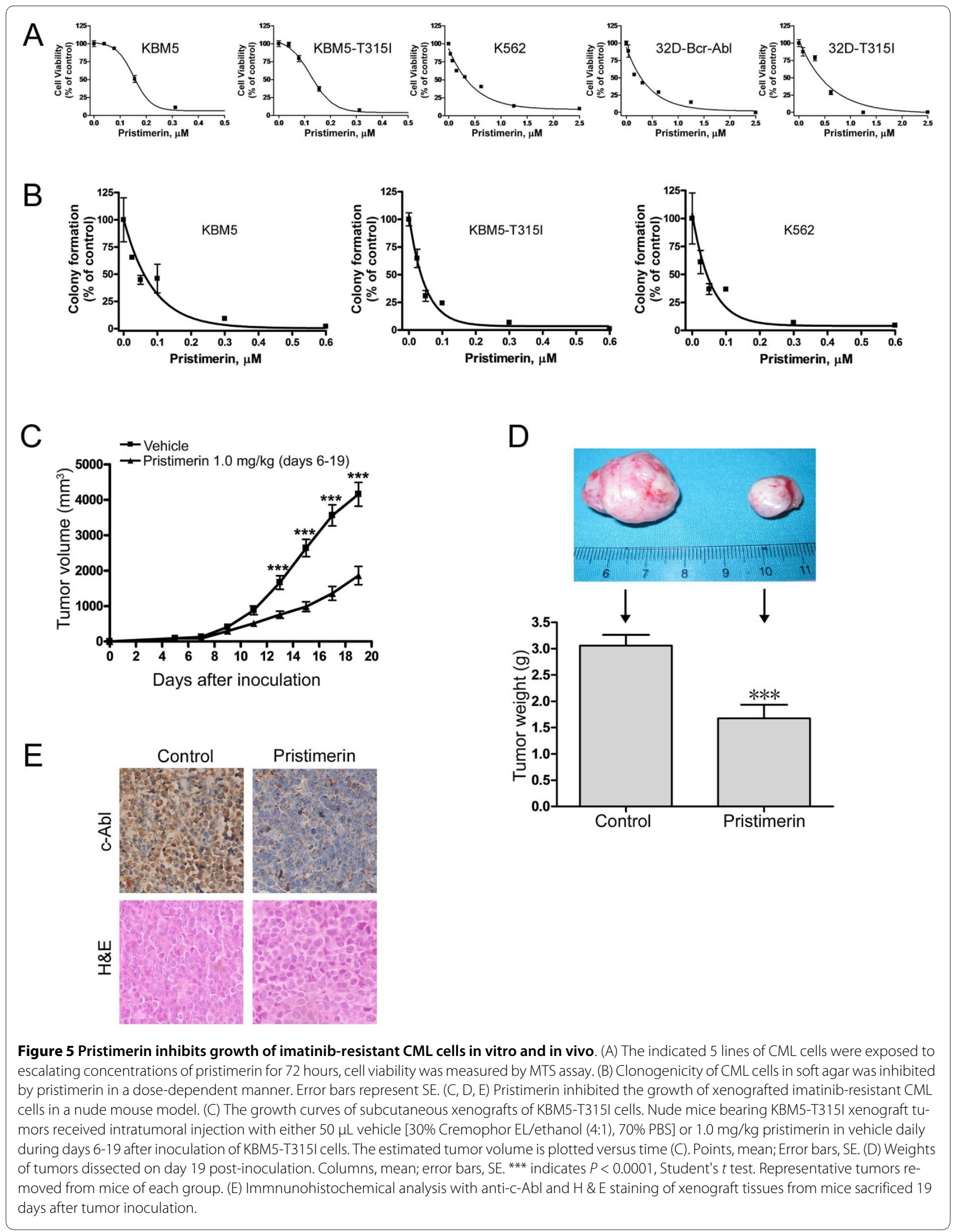


Table 1: IC 50 values of primary leukemia cells from patients with leukemia to pristimerin.

\begin{tabular}{|c|c|c|c|c|}
\hline Patient no. & Diagnosis & Imatinib sensitive & Imatinib resistance & IC50 (nM) \\
\hline 1 & $\mathrm{CML}$ & & $x$ & 578 \\
\hline 2 & CML & $x$ & & 6.28 \\
\hline 3 & $\mathrm{CML}$ & $x$ & & 326 \\
\hline 4 & $\mathrm{CML}$ & $x$ & & 186 \\
\hline 5 & $\mathrm{CML}$ & $x$ & & 210 \\
\hline 6 & JMML & & & 326 \\
\hline 7 & ALL & & & 205 \\
\hline
\end{tabular}

Note: CML, chronic myelogeneous leukemia; JMML, juvenile myelomonocytic leukemia; ALL, acute lymphoid leukemia.

KBM5-T315I cells. The growth curves (the estimated tumor size calculated from the tumor dimension versus time) are shown in Figure 5C. Pristimerin potently inhibited the growth of KBM5-T315I tumors. The weight of tumors was significantly lower in the treated group than in the control (vehicle) group (Figure 5D, $P<0.0001$ ). Immnunohistochemical analysis with an anti-c-Abl antibody (to detect both c-Abl and Bcr-Abl) revealed that cAbl immunoreactivity was markedly decreased by pristimerin treatment (Figure 5E). These data again pointed to the antitumor activity of pristimerin.

\section{Pristimerin does not affect cell cycling}

After exposing CML cells to various concentrations of pristimerin for 24 hours, cell cycle analysis was conducted by using flow cytometry with propidium iodide staining. The results revealed no significant cell cycle alteration in CML cells treated with various concentrations of pristimerin for 24 hours except for the appearance of the sub-G1 apoptotic population (Figure 6).

\section{Pristimerin induced apoptosis in imatinib-sensitive and imatinib-resistant CML cells}

The ability for pristimerin to induce apoptosis in CML cells was assessed by flow cytometry after staining with Annexin $\mathrm{V}$ and propidium iodide. After treatment with pristimerin apoptosis was induced in a dose- and timedependent manner (Figure 7A, 7B) in the CML cells. In parallel, Western blotting analysis revealed that pristimerin induced a dose-dependent specific cleavage of PARP, which is a hallmark of apoptosis (Figure 7C). Concomitantly, pristimerin led to a decline of the precursor form of caspase-3, reflecting its activation.

Most chemotherapeutic agents induced apoptosis by triggering release of cytochrome $\mathrm{c}$ and AIF from mitochondria into the cytosol. To evaluate the apoptosis pathway activated by pristimerin, CML cells were exposed to pristimerin, cytochrome $\mathrm{c}$ and AIF in the cytosolic frac- tion was examined by Western blotting at different time points. Cytochrome $\mathrm{c}$ and AIF were undetectable in the cytosol of control cells, but were released from the mitochondria into the cytosol after pristimerin treatment (Figure 7D). The results implied that pristimerin triggered the mitochondrial pathway of apoptosis. Pristimerin activated the same apoptotic pathway in breast cancer cells as reported by Wu C et al. [21] The effect of pristimerin on antiapoptotic proteins $\left(\mathrm{Bcl}-2, \mathrm{Bcl}-\mathrm{X}_{\mathrm{L}}, \mathrm{Mcl}-\right.$ 1 , survivin) of the $\mathrm{Bcl}-2$ gene family regulating the mitochondrial pathway of apoptosis was also examined. Pristimerin treatment decreased the levels of Bcl- $\mathrm{X}_{\mathrm{L}}$ and $\mathrm{Mcl}$ 1 in a dose- and time-dependent manner without affecting Bcl-2, XIAP, Bax and survivin (Figure 7E and 7F).

\section{Discussion}

The prognosis of CML resistant to imatinib is poor [8]. Bcr-Abl-T315I mutation is a major cause to confer resistance to STI571 as well as the second generation of tyrosine kinase inhibitors. NF- $\mathrm{kB}$ may represent an important mechanism to prevent apoptosis in tumor cells. In the present study, we discovered that pristimerin potently blocked NF- $\mathrm{kB}$ signaling and dramatically downregulated $\mathrm{Bcr}-\mathrm{Abl} \mathrm{mRNA}$ regardless of the mutational status of $\mathrm{Bcr}-\mathrm{Abl}$, inhibited growth and induced apoptosis in CML cells harboring wild-type Bcr-Abl or Bcr-Abl-T315I mutation. We confirmed this activity with two pairs of CML cell lines (KBM5 versus KBM5-T315I, 32D-Bcr-Abl versus 32D-Bcr-Abl-T315I) and primary cells from CML patients. Additionally, pristimerin inhibited the growth of imatinib-resistant Bcr-Abl-T315I in nude mouse xenografts. To our knowledge, this is the first report to show that pristimerin is effective in vitro and in vivo against CML cells, including those with the T315I mutation. Because none of the currently available tyrosine kinase inhibitors in clinical use are effective against CML cells bearing T315I-Bcr-Abl, our findings are of particular interest. 


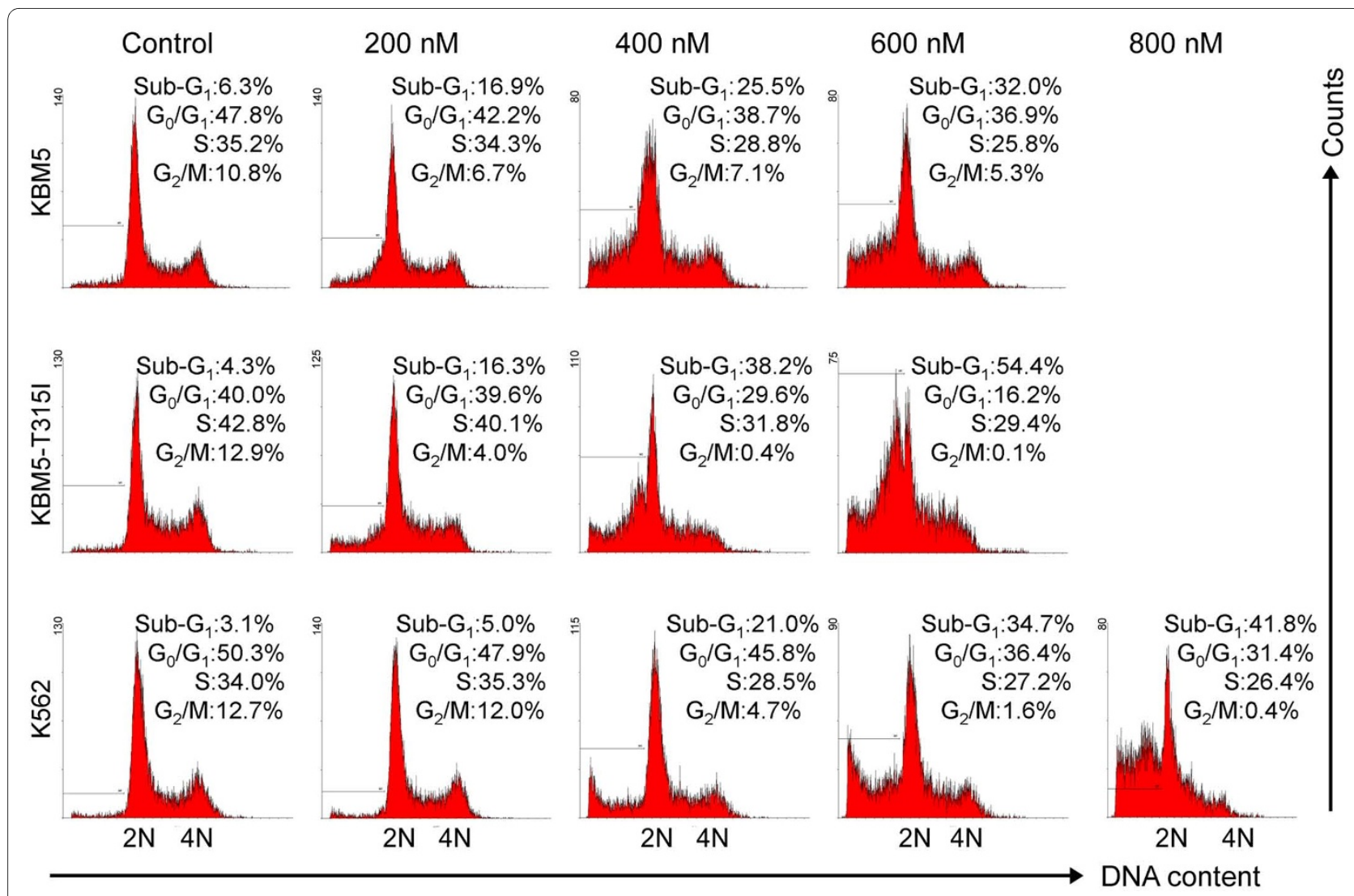

Figure 6 Effect of pristimerin on cell cycling in CML cells. KBM5, KBM5-T315I or K562 cells were treated with pristimerin at the indicated concentrations for 24 hours, cell cycling was analyzed by flow cytometry after staining with propidium iodide. Graphs show data from a representative experiment.

Inhibition of proteasomes was reported as a mechanism by which pristimerin induces apoptosis in prostate cancer cells [34]. However, inhibition of proteasome occurs at micromolar concentrations (pristimerin at 2.2$3.0 \mu \mathrm{M}$ inhibited $50 \%$ of the proteolytic activity of purified $20 \mathrm{~S}$ proteasome; pristimerin at $5.0 \mu \mathrm{M}$ inhibited proteasomal activity by $30 \%-40 \%$ in tumor cells [34]) while the inhibition of Bcr-Abl transcription and inactivation of NF- $\mathrm{kB}$ signaling occur in nanomolar concentrations (Figures 3 and 4). Moreover, no increased cell death in CML cells was observed when pristimerin was combined with MG-132 (a proteasome inhibitor). Therefore, inhibition of proteasomes is unlikely to be a relevant mechanism by which pristimerin induces apoptosis in CML cells.

The inhibitory action of pristimerin against NF- $\mathrm{kB}$ has been documented in murine macrophages (RAW 264.7) induced by lipopolysaccharide [18] and in human myeloma cells induced by TNFa [20]. In these previous reports, only NF- $\mathrm{kB}$-dependent reporter gene assay and EMSA data were reported; the precise steps in NF- $\mathrm{kB}$ signaling that were inhibited by pristimerin were not ascertained. In this study, we thoroughly examined the effect of pristimerin on NF- $\mathrm{kB}$ signaling beyond NF- $\mathrm{kB}$-depen- dent gene reporter and DNA binding of NF-kB (EMSA)

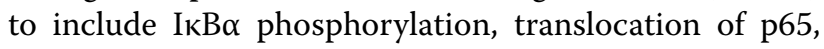
and expression of NF-KB-regulated genes. We pinpointed the precise steps at which pristimerin exerted its inhibitory action in the signaling cascade of NF- $k B$ : TAK1TIKK and IККТІкB $\alpha$ (Figure 3A; Model in Figure 4H).

Oncogenic mutations such as Bcr-Abl, PDGFR $\alpha$, KIT, and Ras have been demonstrated to lead to constitutive activation of NF-kB [16], [35-38]. Reuther et al. demonstrated that NF-kB activation was essential for Bcr-Ablinduced transformation [37]. Inactivation of Bcr-Abl, Flt3 and PDGFR $\alpha$ by specific inhibitors can ablate the NF- $\mathrm{kB}$ activation [12]. By this potential mechanism, rapid decrease of Bcr-Abl by pristimerin may cause or enhance inactivation of NF- $\mathrm{kB}$ signaling. Despite the fact that BcrAbl kinase is sufficient to elicit constitutive activation of NF- $\mathrm{kB}, \mathrm{NF}-\mathrm{kB}$ activation may also occur via an oncogenic mutations-independent mechanism. For instance, inhibition of Flt3 by its inhibitor AG1296 in primary AML blast cells variably affected constitutive NF- $\mathrm{kB}$ activation, indicating that a Flt3-independent mechanism of NF- $\mathrm{kB}$ activation existed [35,39]. Additionally, cytokines including TNF $\alpha$ are increased in the serum of patients with CML 


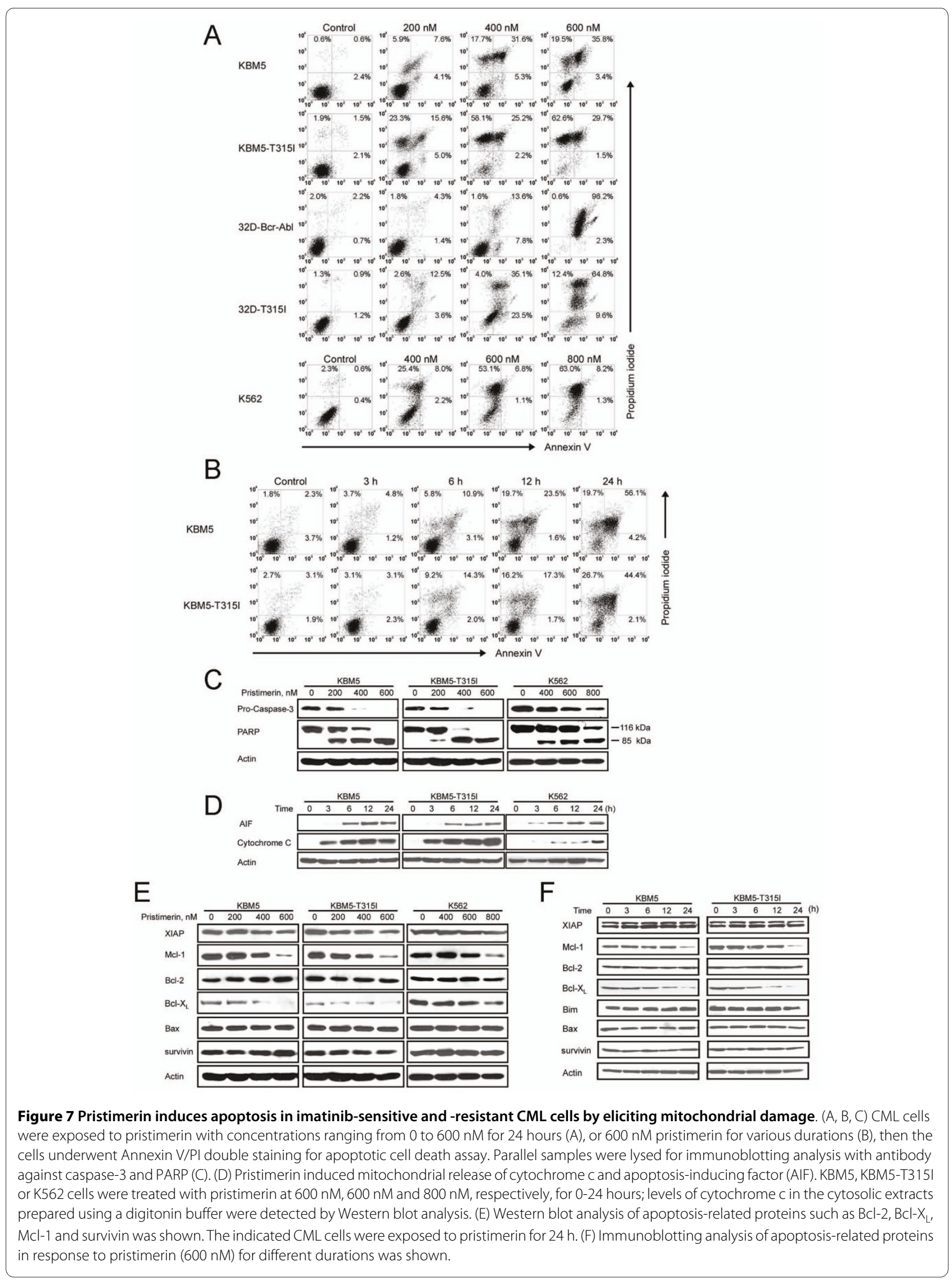


compared with healthy individuals [40]. The abnormal microenvironment in CML bone marrow likely causes deregulated secretion of cytokines by stromal cells [41]. Of note, our data revealed that inactivation of Bcr-Abl by imatinib did not interfere with the TNF $\alpha$-induced NF- $\mathrm{kB}$ activation as reflected by ІкB $\alpha$ phosphorylation and subsequent relocation of p65. Moreover, silencing p65 did not affect the levels of Bcr-Abl. Together, our results implicate that NF- $\mathrm{KB}$ inactivation and Bcr-Abl inhibition may be parallel pathways for pristimerin actions. Future work should assess the relative importance of these two mechanisms.

Pristimerin decreased mRNA of Bcr-Abl. Our data did not support that pristimerin is a global transcription inhibitor (e.g. triptolide [42] and flavopiridol [33]), because pristimerin treatment did not affect the activity of RNA polymerase (Figure 4B) and pristimerin did not inhibit the mRNA of Sirt1 (an unrelated gene, Figure 4E). These results suggest a relatively specific activity of pristimerin against Bcr-Abl mRNA. Further research will be required to identify the precise mechanism by which pristimerin decreases Bcr-Abl mRNA.

$\mathrm{CML}$, being highly dependent on presence of $\mathrm{Bcr}-\mathrm{Abl}$, is one of the typical models of oncogene addiction [43]. Inactivation of Bcr-Abl kinase by tyrosine kinase inhibitors (e.g. imatinib, dasatinib) or downregulating the total levels of cellular Bcr-Abl by pristimerin, triptolide [22] and flavopiridol [33] (at the mRNA level), 17-AAG [44] (at the protein level) could be effective approaches to block "addictive oncogene" in Bcr-Abl-expressing cells. Although pristimerin, triptolide, flavopiridol and 17AAG may impact multiple molecules, Bcr-Abl downregultion is the common effect and is likely the major factor inducing apoptosis in Bcr-Abl-expressing cells. The decrease of Bcr-Abl preceded the onset of apoptosis, suggesting that Bcr-Abl may be the cause and not a consequence of apoptosis in CML cells. Nevertheless, pristimerin is effective in killing imatinib-resistant CML cells bearing T315I Bcr-Abl. Furthermore, pristimerin may be effective against CML cells bearing the Bcr-Abl with mutations other than T315I because of its effect on $\mathrm{Bcr}-\mathrm{Abl} \mathrm{mRNA}$, and this remains to be confirmed. It also remains to be investigated whether pristimerin has activity against CML stem cells, which is believed to be a critical cause of imatinib-resistance and an obstacle to curing CML.

Pristimerin has been tested in vivo by us (Figure 5) and others [20]. Suppression of tumor growth in mice treated with pristimerin without causing death of the mice is proof that a therapeutic window exists. The cytotoxicity of pritimerin against normal bone marrow cells suggests that bone marrow suppression may be a potential side effect of pristimerin. The translational potential of pristimerin to clinical use will depend on its toxicity profile in
Phase I trials. At the very least, pritimerin is a lead compound for further development of triterpenoid-derived anticancer agents. In the future, it will be interesting to examine whether bone marrow protective agents are helpful in counteracting this side effect of pristimerin. Modifying the structure of pristimerin may be an alternative approach to decrease the toxicity of the compound.

\section{Conclusions}

In summary, our findings together showed that pristimerin had an activity against CML cells bearing wildtype or Bcr-Abl-T315I mutation. The mechanisms might involve inhibition of NF- $\mathrm{KB}$ and Bcr-Abl. We concluded that pristimerin could be a lead compound that merited further development to overcome the imatinib-resistance of CML patients.

\section{Additional material}

Additional file 1 Table S1. Characteristics of patients with leukemia. Summary of clinical characteristics of patients with leukemia.

\section{Abbreviations}

AIF: apoptosis-inducing factor; ALL: acute lymphoid leukemia; AML: acute myelogeneous leukemia; CML: chronic myelogeneous leukemia; EMSA: electrophoretic mobility shift assay; FCS: fetal calf serum; JMML: juvenile myelomonocytic leukemia; NF-kB: nuclear factor KB; PCNA: proliferating cell nuclear antigen; RT-qPCR: reverse transcription quantitative real-time PCR; TNFa: tumor necrosis factor $a$

\section{Competing interests}

The authors declare that they have no competing interests.

\section{Authors' contributions}

ZL performed experiments presented in Figures 4, 5, 6, 7; YJ performed experiments presented in Figures 1, 2, 3, 4; CC and JL provided leukemia patient specimens and relevant clinical data, and analyzed the data; QC performed experiments of RT-qPCR in Figure 4E; JP designed, performed research, analyzed data, directed the whole study and wrote the manuscript. All the authors read and proved the final manuscript.

\section{Acknowledgements}

We thank Drs. Mong-Hong Lee (The University of Texas MD Anderson Cancer Center) and Shilai Bao (Institute of Genetics and Developmental Biology, Chinese Academy of Sciences) for generously providing plasmids of pNF-KB-luc, pCMV5-IKKa, pCMV5-IKKß, pCMV5-IKKy, pCMV5-p65, and pCMV5-myc-TAK1. This study was supported by grants from the National High Technology Research and Development Program of China (863 Program grant 2008AA02Z420 to J. Pan), the Major Research Plan of the National Natural Science Fund of China (grant 90713036 to J. Pan), and the National Basic Research Program of China (973 Program grant 2009CB825506 to J. Pan). The authors thank Dr. S. C. J. Yeung (The University of Texas M. D. Anderson Cancer Center, Houston, TX, USA) for a critical reading of the manuscript.

\section{Author Details}

'Department of Pathophysiology, Zhongshan School of Medicine, Sun Yat-sen University, Guangzhou, PR China, 2Department of Pediatrics, Sun Yat-sen memorial Hospital, Sun Yat-sen University, Guangzhou, PR China and ${ }^{3}$ Department of Hematology, The First Affiliated Hospital, Sun Yat-sen University, Guangzhou, PR China

Received: 19 February 2010 Accepted: 19 May 2010 Published: 19 May 2010 


\section{References}

1. Melo JV, Barnes DJ: Chronic myeloid leukaemia as a model of disease evolution in human cancer. Nat Rev Cancer 2007, 7:441-453.

2. Quintas-Cardama A, Cortes J: Molecular biology of bcr-abl1-positive chronic myeloid leukemia. Blood 2009, 113:1619-1630.

3. Quintas-Cardama A, Kantarjian H, Cortes J: Flying under the radar: the new wave of BCR-ABL inhibitors. Nat Rev Drug Discov 2007, 6:834-848.

4. Lugo TG, Pendergast AM, Muller AJ, Witte ON: Tyrosine kinase activity and transformation potency of bcr-abl oncogene products. Science 1990, 247:1079-1082.

5. Baselga J, Arribas J: Treating cancer's kinase 'addiction'. Nat Med 2004 10:786-787.

6. Druker BJ: Circumventing resistance to kinase-inhibitor therapy. NEngl J Med 2006, 354:2594-2596.

7. Druker BG, O'Brien SRL: Long-term benefits of imatinib (IM) for patients newly diagnosed with chronic myelogenous leukemia in chronic phase (CML-CP):The 5-year update from the IRIS study [Abstract]. J Clin Oncol 2006, 24:185.

8. Kantarjian HM, Talpaz M, Giles F, O'Brien S, Cortes J: New insights into the pathophysiology of chronic myeloid leukemia and imatinib resistance. Ann Intern Med 2006, 145:913-923.

9. Morinaga K, Yamauchi T, Kimura S, Maekawa T, Ueda T: Overcoming imatinib resistance using Src inhibitor CGP76030, Abl inhibitor nilotinib and Abl/Lyn inhibitor INNO-406 in newly established K562 variants with BCR-ABL gene amplification. Int J Cancer 2008, 122:2621-2627.

10. Talpaz M, Shah NP, Kantarjian H, Donato N, Nicoll J, Paquette R, O'Cortes J, Brien S, Nicaise C, Bleickardt E, Blackwood-Chirchir MA, lyer V, Chen TT, Huang F, Decillis AP, Sawyers CL: Dasatinib in imatinib-resistant Philadelphia chromosome-positive leukemias. N Eng/ J Med 2006, 354:2531-2541.

11. Kaur P, Feldhahn N, Zhang B, Trageser D, Muschen M, Pertz V, Groffen J, Heisterkamp N: Nilotinib treatment in mouse models of P190 Bcr/Abl lymphoblastic leukemia. Mol Cancer 2007, 6:67.

12. Lounnas N, Frelin C, Gonthier N, Colosetti P, Sirvent A, Cassuto JP, Berthier F, Sirvent N, Rousselot P, Dreano M, Peyron JF, Imbert V: NF-kappaB inhibition triggers death of imatinib-sensitive and imatinib-resistant chronic myeloid leukemia cells including T315I Bcr-Abl mutants. Int $J$ Cancer 2009, 125:308-317.

13. Guzman ML, Rossi RM, Neelakantan S, Li X, Corbett CA, Hassane DC, Becker MW, Bennett JM, Sullivan E, Lachowicz JL, Vaughan A, Sweeney CJ, Matthews W, Carroll M, Liesveld JL, Crooks PA, Jordan CT: An orally bioavailable parthenolide analog selectively eradicates acute myelogenous leukemia stem and progenitor cells. Blood 2007, 110:4427-4435

14. Staudt LM: The molecular and cellular origins of Hodgkin's disease. $J$ Exp Med 2000, 191:207-212.

15. Guzman ML, Neering SJ, Upchurch D, Grimes B, Howard DS, Rizzieri DA, Luger SM, Jordan CT: Nuclear factor-kappaB is constitutively activated in primitive human acute myelogenous leukemia cells. Blood 2001, 98:2301-2307.

16. Kirchner D, Duyster J, Ottmann O, Schmid RM, Bergmann L, Munzert G: Mechanisms of Bcr-Abl-mediated NF-kappaB/Rel activation. Exp Hematol 2003, 31:504-511

17. Cilloni D, Messa F, Arruga F, Defilippi I, Morotti A, Messa E, Carturan S, Giugliano E, Pautasso M, Bracco E, Rosso V, Sen A, Martinelli G, Baccarani M, Saglio G: The NF-kappaB pathway blockade by the IKK inhibitor PS1145 can overcome imatinib resistance. Leukemia 2006, 20:61-67.

18. Dirsch VM, Kiemer AK, Wagner H, Vollmar AM: The triterpenoid quinonemethide pristimerin inhibits induction of inducible nitric oxide synthase in murine macrophages. Eur J Pharmacol 1997 336:211-217.

19. Costa PM, Ferreira PM, Bolzani S Vda, Furlan M, de Freitas Formenton Macedo Dos Santos VA, Corsino J, de Moraes MO, Costa-Lotufo LV Montenegro RC, Pessoa C: Antiproliferative activity of pristimerin isolated from Maytenus ilicifolia (Celastraceae) in human HL-60 cells. Toxicol In Vitro 2008, 22:854-863.

20. Tiedemann RE, Schmidt J, Keats JJ, Shi CX, Zhu YX, Palmer SE, Mao X Schimmer AD, Stewart AK: Identification of a potent natural triterpenoid inhibitor of proteosome chymotrypsin-like activity and NF-kappaB with antimyeloma activity in vitro and in vivo. Blood 2009, 113:4027-4037
21. Wu CC, Chan ML, Chen WY, Tsai CY, Chang FR, Wu YC: Pristimerin induces caspase-dependent apoptosis in MDA-MB-231 cells via direct effects on mitochondria. Mol Cancer Ther 2005, 4:1277-1285.

22. Shi X, Jin Y, Cheng C, Zhang H, Zou W, Zheng Q, Lu Z, Chen Q, Lai Y, Pan J: Triptolide inhibits Bcr-Abl transcription and induces apoptosis in STI571-resistant chronic myelogenous leukemia cells harboring T315I mutation. Clin Cancer Res 2009, 15:1686-1697.

23. Lu Z, Jin Y, Qiu L, Lai Y, Pan J: Celastrol, a novel HSP90 inhibitor, depletes Bcr-Abl and induces apoptosis in imatinib-resistant chronic myelogenous leukemia cells harboring T315I mutation. Cancer Lett 2010, 290:182-191.

24. Jin Y, Lu Z, Ding K, Li J, Du X, Chen C, Sun X, Wu Y, Zhou J, Pan J: Antineoplastic mechanisms of niclosamide in acute myelogenous leukemia stem cells: inactivation of the NF-kappaB pathway and generation of reactive oxygen species. Cancer Res 2010, 70:2516-2527.

25. Pan J, Quintas-Cardama A, Kantarjian HM, Akin C, Manshouri T, Lamb P, Cortes JE, Tefferi A, Giles FJ, Verstovsek S: EXEL-0862, a novel tyrosine kinase inhibitor, induces apoptosis in vitro and ex vivo in human mast cells expressing the KIT D816V mutation. Blood 2007, 109:315-322.

26. Blonska M, Shambharkar PB, Kobayashi M, Zhang D, Sakurai H, Su B, Lin X: TAK1 is recruited to the tumor necrosis factor-alpha (TNF-alpha) receptor 1 complex in a receptor-interacting protein (RIP)-dependent manner and cooperates with MEKK3 leading to NF-kappaB activation. J Biol Chem 2005, 280:43056-43063.

27. Jin Y, Lu Z, Cao K, Zhu Y, Chen Q, Zhu F, Qian C, Pan J: The antitumo activity of homoharringtonine against human mast cells harboring the KIT D816V mutation. Mol Cancer Ther 2010, 9:211-223.

28. Pan J, She M, Xu ZX, Sun L, Yeung SC: Farnesyltransferase inhibitors induce DNA damage via reactive oxygen species in human cancer cells. Cancer Res 2005, 65:3671-3681.

29. Sakurai H, Miyoshi H, Toriumi W, Sugita T: Functional interactions of transforming growth factor beta-activated kinase 1 with IkappaB kinases to stimulate NF-kappaB activation. J Bio/ Chem 1999. 274:10641-10648.

30. Anand P, Kunnumakkara AB, Harikumar KB, Ahn KS, Badmaev V, Aggarwal BB: Modification of cysteine residue in $\mathrm{p} 65$ subunit of nuclear factorkappaB (NF-kappaB) by picroliv suppresses NF-kappaB-regulated gene products and potentiates apoptosis. Cancer Res 2008, 68:8861-8870.

31. Karin M: Nuclear factor-kappaB in cancer development and progression. Nature 2006, 441:431-436.

32. Shambharkar PB, Blonska M, Pappu BP, Li H, You Y, Sakurai H, Darnay BG Hara $\mathrm{H}$, Penninger J, Lin X: Phosphorylation and ubiquitination of the IkappaB kinase complex by two distinct signaling pathways. EMBO J 2007, 26:1794-1805.

33. Chen R, Gandhi V, Plunkett W: A sequential blockade strategy for the design of combination therapies to overcome oncogene addiction in chronic myelogenous leukemia. Cancer Res 2006, 66:10959-10966.

34. Yang H, Landis-Piwowar KR, Lu D, Yuan P, Li L, Reddy GP, Yuan X, Dou QP: Pristimerin induces apoptosis by targeting the proteasome in prostate cancer cells. J Cell Biochem 2008, 103:234-244.

35. Birkenkamp KU, Geugien M, Schepers H, Westra J, Lemmink HH, Vellenga E: Constitutive NF-kappaB DNA-binding activity in AML is frequently mediated by a Ras/PI3-K/PKB-dependent pathway. Leukemia 2004, 18:103-112.

36. Dai Y, Rahmani M, Pei XY, Dent P, Grant S: Bortezomib and flavopiridol interact synergistically to induce apoptosis in chronic myeloid leukemia cells resistant to imatinib mesylate through both $\mathrm{Bcr} / \mathrm{Abl}-$ dependent and -independent mechanisms. Blood 2004, 104:509-518.

37. Reuther JY, Reuther GW, Cortez D, Pendergast AM, Baldwin AS Jr: A requirement for NF-kappaB activation in Bcr-Abl-mediated transformation. Genes Dev 1998, 12:968-981

38. Tanaka A, Konno M, Muto S, Kambe N, Morii E, Nakahata T, Itai A, Matsuda H: A novel NF-kappaB inhibitor, IMD-0354, suppresses neoplastic proliferation of human mast cells with constitutively activated c-kit receptors. Blood 2005, 105:2324-2331.

39. Griessinger E, Imbert V, Lagadec P, Gonthier N, Dubreuil P, Romanelli A, Dreano M, Peyron JF: AS602868, a dual inhibitor of IKK2 and FLT3 to target AML cells. Leukemia 2007, 21:877-885.

40. Kiersnowska-Rogowska B, Izycka A, Jablonska E, Rogowski F, Parfienczyk A: Estimation of level of soluble form PECAM-1, ICAM-2 and TNF-alpha, IL-18 in serum patients with chronic myelogenic leukemia. Przeg/ Lek 2005, 62:772-774. 
41. Bhatia R, McGlave PB, Dewald GW, Blazar BR, Verfaillie CM: Abnormal function of the bone marrow microenvironment in chronic myelogenous leukemia: role of malignant stromal macrophages. Blood 1995, 85:3636-3645

42. Pan J: RNA polymerase - an important molecular target of triptolide in cancer cells. Cancer Lett 2010, 292:149-152.

43. Sawyers CL: Shifting paradigms, the seeds of oncogene addiction. Nat Med 2009, 15:1158-1161.

44. An WG, Schulte TW, Neckers LM: The heat shock protein 90 antagonist geldanamycin alters chaperone association with p210bcr-abl and v-src proteins before their degradation by the proteasome. Cell Growth Differ 2000, 11:355-360.

doi: $10.1186 / 1476-4598-9-112$

Cite this article as: Lu et al., Pristimerin induces apoptosis in imatinib-resistant chronic myelogenous leukemia cells harboring T315I mutation by blocking NF-?B signaling and depleting Bcr-Abl Molecular Cancer 2010, 9:112

Submit your next manuscript to BioMed Central and take full advantage of:

- Convenient online submission

- Thorough peer review

- No space constraints or color figure charges

- Immediate publication on acceptance

- Inclusion in PubMed, CAS, Scopus and Google Scholar

- Research which is freely available for redistribution

Submit your manuscript at www.biomedcentral.com/submit
C Biomed Central 